\title{
Erratum to: Seeking Medical Information Using Mobile Apps and the Internet: Are Family Caregivers Different from the General Public?
}

\author{
Hyunmin Kim $^{1}$ - M. Paige Powell ${ }^{1}$ Soumitra S. Bhuyan ${ }^{1}$
}

Published online: 9 March 2017

(C) Springer Science+Business Media New York 2017

Erratum to: J Med Syst (2017) 41:38

DOI 10.1007/s10916-017-0684-9

Soumitra Sudip Bhuyan should be removed from the author group since the name of the author was listed twice as Soumitra S. Bhuyan. Additionally, the word "Management" in the author's affiliation was misspelled. The original article was corrected.

The online version of the original article can be found at http://dx.doi. org/10.1007/s10916-017-0684-9

Soumitra S. Bhuyan

sbhuyan@memphis.edu

1 Division of Health Systems Management and Policy, The University of Memphis School of Public Health, Memphis, TN, USA 